\title{
Absolute Counts of Peripheral Lymphocyte Subsets Correlate with the Progression-Free Survival and Metastatic Status of Pancreatic Neuroendocrine Tumour Patients
}

This article was published in the following Dove Press journal:

Cancer Management and Research

\author{
Yitao Gong ${ }^{1-4, *}$ \\ Zhiyao Fan $^{1-4, *}$ \\ Guopei Luo (D) $1-4, *$ \\ Qiuyi Huang ${ }^{1-4}$ \\ Yunzhen Qian ${ }^{1-4}$ \\ He Cheng ${ }^{\text {I-4 }}$ \\ Kaizhou Jin ${ }^{1-4}$ \\ Quanxing $\mathrm{Ni}^{1-4}$ \\ Xianjun $\mathrm{Yu} \mathbb{( D D}^{1-4}$ \\ Chen Liu (iD) ${ }^{1-4}$
}

'Department of Pancreatic Surgery, Fudan University Shanghai Cancer Center, Shanghai 200032, People's Republic of China; ${ }^{2}$ Department of Oncology, Shanghai Medical College, Fudan University, Shanghai 200032, People's Republic of China; ${ }^{3}$ Shanghai Pancreatic Cancer Institute, Shanghai 200032, People's Republic of China; ${ }^{4}$ Pancreatic Cancer Institute, Fudan University, Shanghai 200032, People's Republic of China

*These authors contributed equally to this work
Correspondence: Xianjun Yu; Chen Liu Department of Pancreatic Surgery, Fudan University Shanghai Cancer Center, No. 270 DongAn Road, Shanghai 200032,

People's Republic of China Tel + 862 2I-64I75590 ext I307

$\mathrm{Fax}+8621-6403 \mid 446$

Email yuxianjun@fudanpci.org;

liuchen@fudanpci.org

\begin{abstract}
Purpose: Pancreatic neuroendocrine tumours (panNETs) are rare tumours of pancreas. Lymphocyte subsets in the peripheral blood are reported to reflect tumour prognosis and progression. The objective of the study is to investigate the hypotheses that the levels of peripheral lymphocytes may reflect tumour progression and may predict the prognosis of pancreatic neuroendocrine tumours (panNETs).

Patients and Methods: A retrospective cohort study consisting of 73 patients diagnosed with panNETs was conducted. Kaplan-Meier methods and Log rank tests were used to compare the survival rates, and a Cox regression model was used to perform multivariate analyses.
\end{abstract}

Results: panNET patients with distant metastasis were associated with lower peripheral total $\mathrm{T}$ cell $(\mathrm{p}=0.039)$ and $\mathrm{CD} 4+\mathrm{T}$ cell $(\mathrm{p}=0.006)$ counts. Lower peripheral $\mathrm{B}$ cells $(\mathrm{p}=0.007)$ and higher peripheral NK cell $(p=0.001)$ counts indicated worse progression-free survival (PFS) in Log rank tests. In multivariate analyses, low B cell count (hazard ratio (HR): 6.769, $95 \%$ confidence interval $(\mathrm{CI}): 2.158$ to $21.228, \mathrm{p}=0.001$ ) and high NK cell count (HR: $3.715,95 \%$ CI: 1.164 to $11.855, p=0.027$ ) were independent risk factors for progression. NK cells and B cells were also significantly associated with PFS following radical surgical resection.

Conclusion: Peripheral total $\mathrm{T}$ cell and $\mathrm{CD} 4+\mathrm{T}$ cell counts may reflect the distant metastasis status in panNET patients. The absolute count of peripheral B cells and NK cells may independently predict the progression of panNET patients, making them promising prognostic indicators and potential targets for treatment of panNETs.

Keywords: pancreatic neuroendocrine tumours, panNETs, lymphocyte subsets, progressionfree survival, B cells

\section{Background}

Pancreatic neuroendocrine tumours (panNETs) are rare neuroendocrine neoplasms that arise in the islet of Langerhans. ${ }^{1}$ PanNETs comprise less than $3 \%$ of all pancreatic neoplasms, and the annual incidence rate is less than 1 per 100,000 individuals, but the incidence has steadily increased over the last two decades, partly due to improved diagnostic imaging. ${ }^{1,2}$ Unlike other pancreatic malignancies, which are notorious for their aggressiveness and high mortality rates, panNETs are characterized by their indolent tumour biology and relatively 
better prognosis, with a 5-year survival rate of $42.1 \%$. $^{3}$ PanNETs are dichotomized into functional (F-panNETs) and non-functional (NF-panNETs) based on the hormonal secretion status of the tumour and the resulting clinical symptoms. ${ }^{4}$ According to the new classification of panNETs proposed by the World Health Organization (WHO) in 2017, panNETs can be subcategorized into well-differentiated (G1, G2, or G3) panNETs and poorly differentiated (G3) pancreatic neuroendocrine carcinomas (panNECs). In this study, we mainly focused on well-differentiated panNETs. It is reported that old age, ${ }^{5}$ presence of lymph node and distant metastasis, ${ }^{5,6}$ positive margins, ${ }^{7}$ high fluorodeoxyglucose (FDG) uptake, ${ }^{8}$ and high ki-67 index all negatively correlate with the prognosis of well-differentiated panNETs, and particularly, ki-67 index is a major proliferative factor in panNETs with a significant prognostic value. ${ }^{9}$ However, those traditional parameters for tumour staging do not always satisfactorily predict the prognosis of panNETs, which highlights the need for novel prognostic biomarkers for panNETs.

Tumour progression is a complicated process that involves tumour-host immunological interactions - the host immune status profoundly influences tumour development and vice versa. ${ }^{10}$ Peripheral immune cells are believed to reflect the host immunity in tumour patients, and several reports have demonstrated that peripheral immune cell counts may have a remarkable impact on tumour prognosis. ${ }^{11-13}$

Lymphocyte subpopulations are immune cells that are vital to anti-tumour immunity and include $\mathrm{T}$ cells (that specialize in cellular immunity), B cells (that specialize in humoural immunity) and natural killer (NK) cells (that directly kill tumour cells and virus-infected cells). ${ }^{14-16}$ CD3 $+\mathrm{T}$ cells can be mainly subdivided into 2 subsets according to their immunological functions and cell surface markers: CD8+ $\mathrm{T}$ cells and CD4+ $\mathrm{T}$ cells. CD8+ $\mathrm{T}$ cells are also known as cytotoxic $\mathrm{T}$ cells (identified as $\mathrm{CD}^{+} \mathrm{CD}^{+} \mathrm{T}$ cells), which kill tumour cells by releasing cytokines, cytotoxic granules, or via Fas/FasL interactions. ${ }^{17} \mathrm{CD} 4+\mathrm{T}$ cells (identified as $\mathrm{CD}^{+} \mathrm{CD}^{+}$ $\mathrm{T}$ cells) are commonly divided into conventional $\mathrm{T}$ helper (Th) cells, which play a pivotal role in regulating the immune responses of other immune cells, including cytotoxic T cells, B cells and macrophages, and regulatory $\mathrm{T}$ cells, which are characterized as immunosuppressive lymphocytes that inhibit the activation and proliferation of effector T cells. ${ }^{18} \mathrm{~B}$ cells and NK cells are identified as
$\mathrm{CD}^{-} \mathrm{CD} 19^{+}$cells and $\mathrm{CD}^{-} \mathrm{CD} 16^{+} \mathrm{CD}^{-} 6^{+}$cells, respectively.

Since these lymphocyte subsets strongly correlate with tumour immune surveillance and may thus influence tumourigenesis and tumour progression, ${ }^{19}$ alterations in the levels of peripheral lymphocyte subsets may reflect the state of tumour development and may predict tumour prognosis. The neuroendocrine system plays a critical role in regulating the immune system, which further suggests that the immunological status of the host, which can be reflected by the levels of peripheral lymphocyte subsets, strongly affects the prognosis of neuroendocrine tumour patients. ${ }^{20}$ However, thus far, the prognostic significance of the levels of peripheral lymphocyte subsets in neuroendocrine tumours has not been thoroughly investigated. In this study, we aim to investigate the hypothesis that peripheral lymphocytes may reflect tumour progression and may predict the prognosis of panNETs.

\section{Materials and Methods Design and Patients}

A retrospective, follow-up, cohort study consisting of 78 panNET patients who met the inclusion criteria from May 2009 to January 2018 was conducted at Shanghai Cancer Center, Fudan University, China, and 5 of the participants were lost to follow-up. Ultimately, 73 patients were included in the cohort. The diagnosis of resected panNETs was based on post-operational pathology report, and the diagnosis of patients who did not undergo surgical resection was confirmed by cytological or histological pathology report obtained via endoscopic ultrasoundguided fine-needle aspiration biopsy (EUS-FNA), or percutaneous liver biopsy (PLB) when liver metastasis was present. The inclusion criteria were as follows: (1) patients who were histologically or cytologically diagnosed with panNETs; (2) patients with complete data on peripheral lymphocyte subgroup counts; and (3) patients who received major treatment in our centre, which includes surgical resection and chemotherapy. The exclusion criteria were as follows: (1) patients without follow-up data; (2) patients with poorly differentiated panNECs according to the fifth edition of the WHO classification of tumours; (3) patients with secondary malignancies or multiple primary malignancies; (4) patients with diseases of the immune system or a history of viral or bacterial infections within 2 weeks before major treatments; and (5) patients with haematological disorders. 
We collected baseline clinicopathological data, including sex, age, tumour location, tumour stage, tumour grade, tumour functional status, tumour size, and major treatment received, from the patients' medical history from Shanghai Cancer Center. The tumour grade was determined based on the fifth edition of the WHO Classification of Tumour, and was reviewed by expert pathologists. Tumour sizes were measured according to the last enhanced computed tomography (CT) scans prior to major treatment.

Due to the low number of patient deaths in our cohort, instead of overall survival (OS), PFS was the primary endpoint, which was defined as the length of time from the beginning of treatment to the detection of disease progression or to death from any cause. Disease progression was defined as increase in number/size if pre-existing lesions and/or recurrence after previous radical surgery, and was based on the Response Evaluation Criteria in Solid Tumours (RECIST) criteria (version 1.1) Progression was assessed by imaging (including CT, magnetic resonance imaging (MRI), and 68-Gallium and/or FDG positron emission tomography (PET)/CT). The frequency of imaging re-examinations for each patient varied according to the different tumour stages and treatments. For patients who underwent radical surgery and did not require further treatment, the frequency of follow-up examinations gradually decreased. For patients who needed further treatment, imaging re-examinations were regularly carried out every 3 months.

The objective of this study was to assess the clinical significance of the absolute counts of lymphocyte subsets in the peripheral blood for predicting the prognosis of panNET patients. The additional objectives were to investigate the correlation between the levels of peripheral lymphocyte subsets and sex, age, tumour grade, tumour function, distant metastasis and nodal metastasis.

This study was approved by the Ethics Board of Shanghai Cancer Center, Fudan University, and all patients involved in this study provided informed consent for the use of their personal data for research purposes.

\section{Blood Samples and Flow Cytometry}

We determined the baseline value of the peripheral lymphocyte subset count by the flow cytometric analysis of patient blood samples. Before receiving major treatments, the peripheral blood samples of patients were collected and instantly processed for flow cytometric analysis using a MultiSET IMK Kit (BD Bioscience,
USA). Antibodies (eBioscience, USA) against CD8, CD4, CD3, CD19, CD56 and CD16 were used, and we evaluated the absolute count of each subset. Data analysis was performed using FlowJo. We used CD3+ to represent total $\mathrm{T}$ cells; $\mathrm{CD} 3+\mathrm{CD} 4+$ to represent $\mathrm{CD} 4+$ $\mathrm{T}$ cells; $\mathrm{CD} 3+\mathrm{CD} 8+$ to represent $\mathrm{CD} 8+\mathrm{T}$ cells; CD3$\mathrm{CD} 19+$ to represent $\mathrm{B}$ cells; and $\mathrm{CD} 3-\mathrm{CD} 16+\mathrm{CD} 56+$ to represent NK cells.

\section{Statistical Analyses}

We used the Kaplan-Meier method with a 95\% confidence interval (CI) to estimate PFS. Log rank tests were conducted to compare the survival curves of the two groups. Receiver operating characteristic (ROC) curve analyses were performed to set the cut-off value for each lymphocyte subset. The results of multivariate analyses were evaluated with the Log rank test and Cox regression hazard models. Spearman's rank correlation tests were used to evaluate the correlation between the lymphocyte subset count and clinicopathologic characteristics. All the statistical analyses were performed using SPSS 23.0 software (SPSS, Inc., Chicago, IL). A $p$ value less than 0.05 was considered statistically significant, and all the $\mathrm{p}$ values are two-sided.

\section{Results}

\section{Patient Baseline Characteristics}

Initially, 78 patients with panNETs were included in this study. Among these patients, 5 were lost to follow-up, and the lost-to-follow-up rate was $6.41 \%$. All participants lost to follow-up were removed from the analysis, and 73 patients were ultimately included in the final investigation. The baseline characteristics of the patients are shown in Table 1. The median age of the patients was 50 , ranging from 16 to 77 . Of the 73 participants, $65(89.0 \%)$ had undergone surgical resection, and 8 $(11.0 \%)$ had received non-surgical treatment, which included somatostatin analogue treatment (Octreotide etc.), molecular targeted therapy (Sunitinib etc.), hepatic arterial infusion chemotherapy (HAIC) and transarterial chemoembolization (TACE). Seventeen patients had distant metastases, 14 of which were liver lesions, 1 had pulmonary lesion and 1 had peritoneal lesion; 9 patients with liver metastases had undergone surgical resection. There were 7 patients with functioning panNETs, 1 of them was gastrinoma, and 6 were insulinoma. 
Table I Baseline Characteristics of the Patients

\begin{tabular}{|c|c|c|c|}
\hline Characteristics & Parameters & Number & Percentage \\
\hline \multirow[t]{2}{*}{ Age } & $<60$ (years) & 55 & $75.3 \%$ \\
\hline & $\geq 60$ (years) & 18 & $24.7 \%$ \\
\hline \multirow[t]{2}{*}{ Sex } & Male & 32 & $43.8 \%$ \\
\hline & Female & 41 & $56.2 \%$ \\
\hline \multirow[t]{2}{*}{ Tumor Location } & $\begin{array}{l}\text { Head and Neck of } \\
\text { Pancreas }\end{array}$ & 30 & $41.1 \%$ \\
\hline & $\begin{array}{l}\text { Body and Tail of } \\
\text { Pancreas }\end{array}$ & 43 & $58.9 \%$ \\
\hline \multirow[t]{2}{*}{ Tumor Grade ${ }^{\mathrm{a}}$} & GI & 29 & $39.7 \%$ \\
\hline & G2 & 43 & $58.9 \%$ \\
\hline \multirow[t]{2}{*}{ Ki67 Index } & $\leq 2 \%$ & 31 & $42.5 \%$ \\
\hline & $>2 \%$ & 42 & $57.5 \%$ \\
\hline \multirow[t]{3}{*}{ Nodal Metastasis } & No & 53 & $72.6 \%$ \\
\hline & Yes & 11 & $15.0 \%$ \\
\hline & Unknown & 9 & $12.3 \%$ \\
\hline \multirow{2}{*}{$\begin{array}{l}\text { Distant } \\
\text { Metastasis }\end{array}$} & No & 56 & $76.7 \%$ \\
\hline & Yes & 17 & $23.3 \%$ \\
\hline \multirow[t]{2}{*}{ Tumor Function } & Non-Functional & 66 & $90.4 \%$ \\
\hline & Functional & 7 & $9.6 \%$ \\
\hline \multirow[t]{2}{*}{ Tumor Size } & $\geq 4 \mathrm{~cm}$ & 33 & $45.2 \%$ \\
\hline & $<4 \mathrm{~cm}$ & 40 & $54.8 \%$ \\
\hline \multirow{3}{*}{$\begin{array}{l}\text { Treatment } \\
\text { Received }\end{array}$} & Radical Resection & 58 & $79.4 \%$ \\
\hline & $\begin{array}{l}\text { Non-radical } \\
\text { Resection }\end{array}$ & 7 & $9.6 \%$ \\
\hline & $\begin{array}{l}\text { Non-surgical } \\
\text { Treatment }\end{array}$ & 8 & $11.0 \%$ \\
\hline \multirow{2}{*}{$\begin{array}{l}\text { Total T Cell } \\
\text { Count }\end{array}$} & $\leq 1.07 \times 10^{9} / \mathrm{L}$ & 33 & $45.2 \%$ \\
\hline & $>1.07 \times 10^{9} / \mathrm{L}$ & 40 & $54.8 \%$ \\
\hline \multirow{2}{*}{$\begin{array}{l}\text { CD4+ T Cell } \\
\text { Count }\end{array}$} & $\leq 0.52 \times 10^{9} / \mathrm{L}$ & 21 & $28.8 \%$ \\
\hline & $>0.52 \times 10^{9} / \mathrm{L}$ & 52 & $71.2 \%$ \\
\hline \multirow{2}{*}{$\begin{array}{l}\text { CD8+ T Cell } \\
\text { Count }\end{array}$} & $\leq 0.25 \times 10^{9} / \mathrm{L}$ & 13 & $17.8 \%$ \\
\hline & $>0.25 \times 10^{9} / \mathrm{L}$ & 60 & $82.2 \%$ \\
\hline \multirow[t]{2}{*}{ NK Cell Count } & $\leq 0.46 \times 10^{9} / \mathrm{L}$ & 50 & $68.5 \%$ \\
\hline & $>0.46 \times 10^{9} / \mathrm{L}$ & 23 & $31.5 \%$ \\
\hline
\end{tabular}

(Continued)
Table I (Continued).

\begin{tabular}{|l|l|l|l|}
\hline Characteristics & Parameters & Number & Percentage \\
\hline \multirow{2}{*}{ B Cell Count } & $\leq 0.17 \times 10^{9} / \mathrm{L}$ & 33 & $45.2 \%$ \\
\cline { 2 - 4 } & $>0.17 \times 10^{9} / \mathrm{L}$ & 40 & $54.8 \%$ \\
\hline
\end{tabular}

Notes: ${ }^{\mathrm{O} O n e}$ of the patients has lost the data on tumor grade. Cut-off value was set by receiver operating characteristic (ROC) curve analysis.

\section{Correlation of the Baseline Levels of Peripheral Lymphocyte Subsets with Clinicopathologic Parameters}

The statistical correlations between the baseline absolute counts of total T cells, CD4+ T cells, CD8+ T cells, B cells and NK cells and several clinicopathologic parameters were evaluated with Spearman's rank correlation tests and are shown in Supplement Table A1. Distant metastasis negatively correlated with the total $\mathrm{T}$ cell count (Spearman's rho $=-0.242, \mathrm{p}=0.039$ ) and the CD4+ $\mathrm{T}$ cell count (Spearman's rho $=-0.317, \mathrm{p}=0.006$ ). To further confirm this correlation, we used Mann-Whitney U-tests (see Figure 1) to compare the mean absolute counts of the lymphocyte subsets in patients with different distant metastatic statuses. The total $\mathrm{T}$ cell count $(\mathrm{p}=$ $0.039)$ and the CD4+ T count $(p=0.006)$ were significantly lower in patients with distant metastasis than those in patients without distant metastasis. However, the absolute counts of peripheral CD8 $+\mathrm{T}$ cells, NK cells and $\mathrm{B}$ cells did not show significant correlations with clinicopathologic parameters.

\section{Peripheral B Cell and NK Cell Absolute Counts Correlated with Progression-Free Survival in Patients with panNETs}

At the end of the follow-up period, $28(38.4 \%)$ of the participants $(\mathrm{N}=73)$ had progression. The median (range) duration of follow-up after panNETs diagnosis in all patients was 19 months (1.6 to 83 months), and the median (95\% CI) PFS of all patients was 60.0 months (41.6 to 78.4 months). The fraction of progression, median progression-free time of each group and $\mathrm{p}$ value derived from Log rank tests are shown in Table 2. Kaplan-Meier curves of PFS are shown in Figure 2. Log rank tests indicated that the absolute counts of peripheral Total $\mathrm{T}$ cell $(\mathrm{p}=0.036), \mathrm{CD} 4+\mathrm{T}$ cells $(\mathrm{p}=0.006)$ and $\mathrm{B}$ cells 

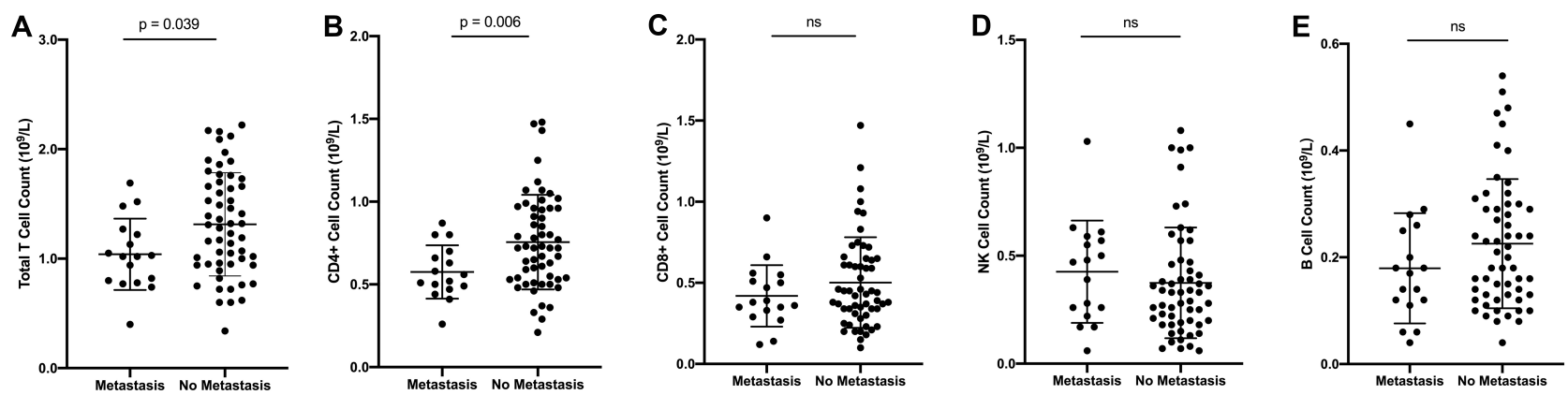

Figure I Difference in mean peripheral lymphocyte levels in patients with or without distant metastasis. (A) Total T cell count in peripheral blood is significantly higher in patients without distant metastasis. (B) CD4+ T cell count in peripheral blood is significantly higher in patients without distant metastasis. (C) CD8+ T cell count in peripheral blood has no significant correlation with distant metastasis. (D) NK cell count in peripheral blood has no significant correlation with distant metastasis. (E) B cell count in peripheral blood has no significant correlation with distant metastasis. Error bars represent the standard deviation. $\mathrm{P}$ values derived from Mann-Whitney $U$-tests.

$(\mathrm{p}=0.007)$ positively correlated with the PFS of patients with panNETs - a higher count indicated a better prognosis; while peripheral NK cell count $(\mathrm{p}=0.001)$ was found negatively associated with the PFS. The absolute counts of peripheral CD8+ $\mathrm{T}$ cells did not significantly correlate with PFS.

\section{Absolute Counts of Peripheral NK Cells and B Cells May Independently Predict the Progression of panNETs}

The results of univariate and multivariate analyses for the PFS of panNET patients based on a Cox regression model are shown in Table 3. In the multivariable-adjusted Cox regression model that included tumour grade, nodal metastasis, distant metastasis and treatment received, the adjusted hazard ratio (HR) for progression comparing those with low versus high peripheral $\mathrm{B}$ cell count and those with low versus high peripheral NK cell count were 6.769 (95\% confidence interval (CI): 2.158 to 21.228$)$ and 3.715 (95\% CI: 1.164 to 11.855 ), respectively, suggesting that a low peripheral B cell count and a high peripheral NK cell count may independently predict progression of panNETs.

\section{Absolute Counts of Peripheral B Cells and NK Cells Were Associated with Progression-Free Survival in panNETs Patients Following Radical Surgical Resection}

To further investigate the prognostic value of peripheral lymphocyte subset counts in patients who had no distant metastatic

Table 2 Progression Fraction and Median Progression-Free Survival of Each Group

\begin{tabular}{|c|c|c|c|c|}
\hline Lymphocytes & Cutoff Values & Progression Fraction & Median PFS (95\% Cl) (Months) & $P$ value \\
\hline \multirow[t]{2}{*}{ Total T Cell } & $\leq 1.07 \times 10^{9} / \mathrm{L}$ & $48.5 \%$ & 48.0 (0 to 97.2$)$ & $0.036^{*}$ \\
\hline & $>1.07 \times 10^{9} / \mathrm{L}$ & $30.0 \%$ & 72.1 (50.4 to 93.8$)$ & \\
\hline \multirow[t]{2}{*}{ CD4+ T Cell } & $\leq 0.52 \times 10^{9} / \mathrm{L}$ & $61.9 \%$ & $35.0(0$ to 74.4$)$ & $0.006^{*}$ \\
\hline & $>0.52 \times 10^{9} / \mathrm{L}$ & $28.8 \%$ & 72.1 (50.5 to 93.7$)$ & \\
\hline \multirow[t]{2}{*}{ CD8+ T Cell } & $\leq 0.25 \times 10^{9} / \mathrm{L}$ & $30.8 \%$ & $67.1(-)$ & 0.245 \\
\hline & $>0.25 \times 10^{9} / \mathrm{L}$ & $40.0 \%$ & $48.2(33.4$ to 63.1$)$ & \\
\hline \multirow[t]{2}{*}{ NK Cell } & $\leq 0.46 \times 10^{9} / \mathrm{L}$ & $26.0 \%$ & 73.1 (48.3 to 98.0$)$ & $0.00 I^{*}$ \\
\hline & $>0.46 \times 10^{9} / \mathrm{L}$ & $65.2 \%$ & $13.3(0$ to 41.6$)$ & \\
\hline \multirow[t]{2}{*}{ B Cell } & $\leq 0.17 \times 10^{9} / \mathrm{L}$ & $48.5 \%$ & $35.0(0$ to 73.1$)$ & $0.007^{*}$ \\
\hline & $>0.17 \times 10^{9} / \mathrm{L}$ & $30.0 \%$ & 72.1 (50.0 to 94.2$)$ & \\
\hline
\end{tabular}

Notes: $* p<0.05$. P value derived from Log rank tests.

Abbreviations: PFS, progression-free survival; $\mathrm{Cl}$, confidence interval. 

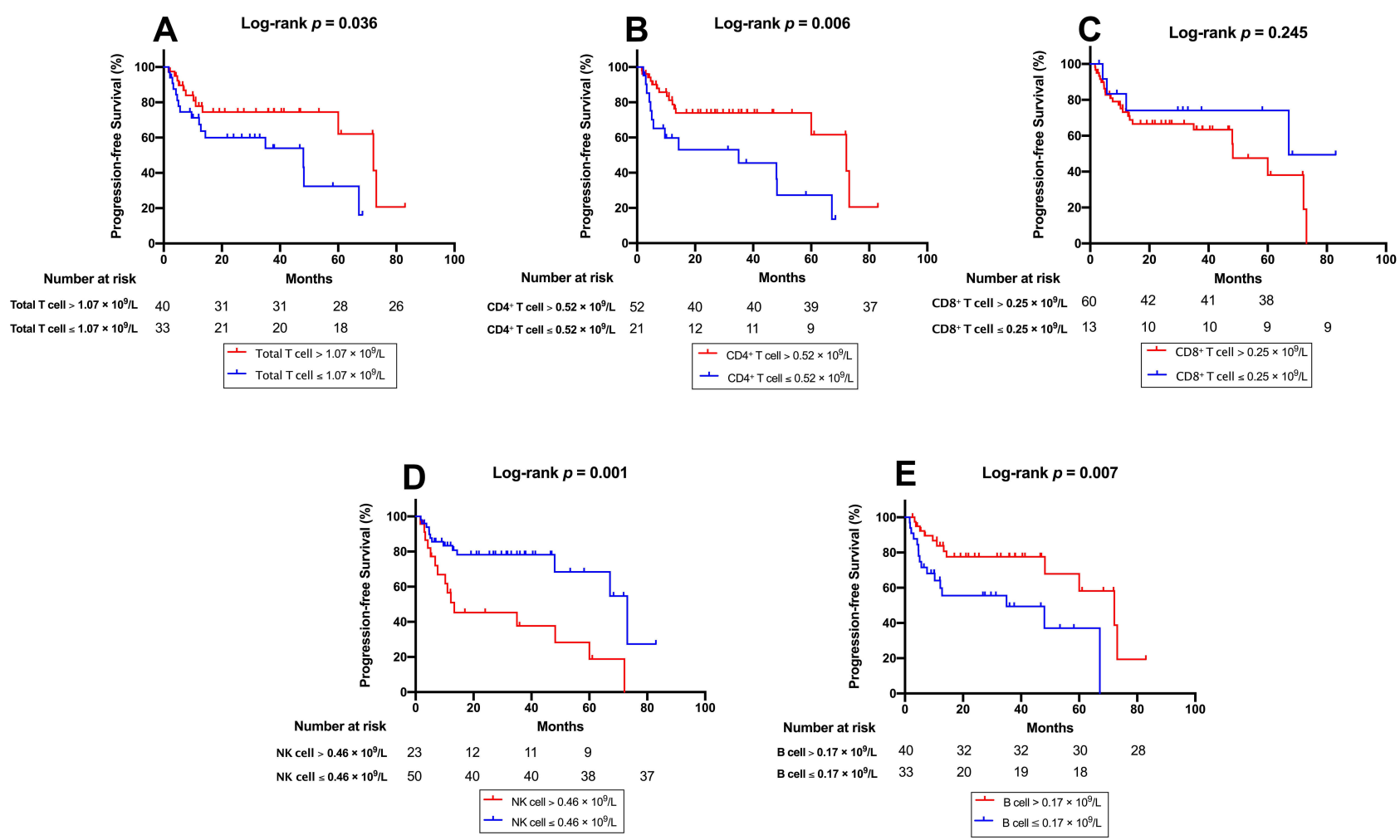

Figure 2 Kaplan-Meier curves for progression-free survival $(n=73)$. (A) Absolute count of peripheral total T cells $>1.07 \times 10^{9} / \mathrm{L}$ and $\leq 1.07 \times 10^{9} / \mathrm{L}$. (B) Absolute count of peripheral CD4+ T cell $>0.52 \times 10^{9} / \mathrm{L}$ and $\leq 0.52 \times 10^{9} / \mathrm{L}$. (C) Absolute count of peripheral CD8+ T cells $>0.25 \times 10^{9} / \mathrm{L}$ and $\leq 0.25 \times 10^{9} / \mathrm{L}$. (D) Absolute count of peripheral NK cells $>0.46 \times 10^{9} / \mathrm{L}$ and $\leq 0.46 \times 10^{9} / \mathrm{L}$. (E) Absolute count of peripheral B cells $>0.17 \times 10^{9} / \mathrm{L}$ and $\leq 0.17 \times 10^{9} / \mathrm{L}$. P value derived from Log rank tests.

sites and underwent radical surgical resection, we studied the subgroup of 56 patients without distant metastasis, and all of them underwent surgical resection. Kaplan-Meier curves of PFS are shown in Figure 3. Log rank tests indicated that high absolute counts of peripheral B cells $(\mathrm{p}=0.011)$ correlated with better PFS of patients with panNETs, while the high peripheral NK cell count $(p=0.018)$ indicated worse PFS of patients with panNETs. The absolute counts of peripheral total T cells, CD8 + T cells and CD4+ cells did not significantly correlate with PFS. The results of univariate and multivariate analyses (Supplement Table A2) for the PFS of panNET patients based on a Cox regression model revealed that high peripheral $\mathrm{NK}$ cell counts $(\mathrm{HR}=11.189,95 \% \mathrm{CI}: 2.334$ to $53.645, \mathrm{p}=$ $0.003)$ and low peripheral B cell counts $(\mathrm{HR}=10.811,95 \% \mathrm{CI}$ : 2.202 to $53.075, \mathrm{p}=0.003$ ) were independent risk factors for PFS in panNET patients who have undergone radical surgical resection.

\section{Discussion}

In this study, we examined the progression-free survival (PFS) of 73 panNET patients and their absolute counts of lymphocyte subsets in the peripheral blood in a retrospective cohort to evaluate the correlation of the prognosis and clinicopathological parameters of panNET patients and the levels of peripheral lymphocyte subsets, thus providing a novel prognostic biomarker for panNETs.

Our study revealed that the absolute counts of total $\mathrm{T}$ cells and CD4+ $\mathrm{T}$ cells strongly correlate with the metastatic status. Patients with distant metastasis tended to have lower total $\mathrm{T}$ cell and CD4+ $\mathrm{T}$ cell counts in the peripheral blood. Our study also demonstrated that a high NK cell count and a low B cell count may predict poor PFS and were independent prognostic factors for PFS after adjusting for tumour grade, nodal metastasis, distant metastasis, and treatment received in both the 73-patient cohort and in the subgroup of patients who had no distant metastases and underwent radical surgical resection; the rest of the subsets did not display significant correlations with PFS in multivariate analyses.

T cells mediate cellular immunity and play a prominent role in anti-tumour immune responses. $\mathrm{T}$ cells can be generally divided into CD4+ T cells, CD8+ T cells, memory $\mathrm{T}$ cells, and natural killer $\mathrm{T}$ cells. CD4+ T cells play a pivotal role in anti-tumour immunity by regulating most 
Table 3 Univariate and Multivariate Analyses for PFS

\begin{tabular}{|c|c|c|c|c|c|c|c|}
\hline \multirow[t]{2}{*}{ Characteristics } & \multirow[t]{2}{*}{ Parameters } & \multicolumn{3}{|c|}{ Univariate Analyses } & \multicolumn{3}{|c|}{ Multivariate Analyses } \\
\hline & & HR & $95 \% \mathrm{Cl}$ & p value & HR & $95 \% \mathrm{Cl}$ & p value \\
\hline \multirow[t]{2}{*}{ Age } & $<60$ (years) & I & & & & & \\
\hline & $\geq 60$ (years) & 0.769 & 0.308 to 1.920 & 0.574 & & & \\
\hline \multirow[t]{2}{*}{ Sex } & Male & I & & & & & \\
\hline & Female & 0.707 & 0.315 to 1.587 & 0.401 & & & \\
\hline \multirow[t]{2}{*}{ Tumor Location } & Head and Neck of Pancreas & 1 & & & & & \\
\hline & Body and Tail of Pancreas & 1.325 & 0.630 to 2.789 & 0.459 & & & \\
\hline \multirow[t]{2}{*}{ Tumor Grade } & Low & 1 & & & 1 & & \\
\hline & Intermediate & 3.328 & 1.260 to 8.790 & $0.015^{*}$ & 1.530 & 0.431 to 5.429 & 0.510 \\
\hline \multirow[t]{3}{*}{ Nodal Metastasis } & No & 1 & & & 1 & & \\
\hline & Yes & 4.160 & 1.602 to 10.800 & $0.003 *$ & 3.191 & 0.971 to 10.482 & 0.056 \\
\hline & Unknown & 12.476 & 4.439 to 35.062 & $<0.001 *$ & 6.996 & 0.559 to 87.626 & 0.131 \\
\hline \multirow[t]{2}{*}{ Distant Metastases } & No & 1 & & & 1 & & \\
\hline & Yes & 17.095 & 6.675 to 38.954 & $<0.00 I^{*}$ & 66.400 & 8.246 to 534.685 & $<0.00 I^{*}$ \\
\hline \multirow[t]{2}{*}{ Tumor Function } & Non-Functional & I & & & & & \\
\hline & Functional & I.III & 0.260 to 4.750 & 0.887 & & & \\
\hline \multirow[t]{2}{*}{ Tumor Size } & $<4 \mathrm{~cm}$ & 1 & & & & & \\
\hline & $\geq 4 \mathrm{~cm}$ & 1.525 & 0.691 to 3.370 & 0.296 & & & \\
\hline \multirow[t]{3}{*}{ Treatment Received } & Radical Resection & 1 & & & 1 & & \\
\hline & Non-radical Resection & 13.614 & 5.023 to 36.894 & $<0.00 I^{*}$ & 0.241 & 0.033 to 1.753 & 0.160 \\
\hline & Non-surgical Treatment & $|3.79|$ & 4.800 to 39.623 & $<0.00 I^{*}$ & 0.056 & 0 to 1.105 & 0.056 \\
\hline \multirow[t]{2}{*}{ Total T Cells } & $>1.07 \times 10^{9} / \mathrm{L}$ & I & & & 1 & & \\
\hline & $\leq 1.07 \times 10^{9} / \mathrm{L}$ & 2.284 & 1.033 to 5.050 & $0.04 I^{*}$ & 0.591 & 0.107 to 3.262 & 0.546 \\
\hline \multirow[t]{2}{*}{ CD4+ T Cells } & $>0.52 \times 10^{9} / \mathrm{L}$ & I & & & & & \\
\hline & $\leq 0.52 \times 10^{9} / \mathrm{L}$ & 2.835 & 1.308 to 6.145 & $0.008^{*}$ & 1.064 & 0.170 to 6.642 & 0.947 \\
\hline \multirow[t]{2}{*}{ CD8+ T Cells } & $>0.25 \times 10^{9} / \mathrm{L}$ & $\mathrm{I}$ & & & & & \\
\hline & $\leq 0.25 \times 10^{9} / \mathrm{L}$ & 1.881 & 0.639 to 5.539 & 0.252 & & & \\
\hline \multirow[t]{2}{*}{ NK cells } & $\leq 0.46 \times 10^{9} / \mathrm{L}$ & 1 & & & I & & \\
\hline & $>0.46 \times 10^{9} / \mathrm{L}$ & 3.287 & 1.530 to 7.060 & $0.002 *$ & 3.715 & 1.164 to 11.855 & $0.027^{*}$ \\
\hline \multirow[t]{2}{*}{ B cells } & $>0.17 \times 10^{9} / \mathrm{L}$ & 1 & & & 1 & & \\
\hline & $\leq 0.17 \times 10^{9} / \mathrm{L}$ & 2.891 & 1.292 to 6.466 & $0.010 *$ & 6.769 & 2.158 to 21.228 & $0.001 *$ \\
\hline
\end{tabular}

Notes: $* p<0.05$. $\mathrm{P}$ value derived from Cox regression: Enter method.

Abbreviations: $\mathrm{Cl}$, confidence interval; $\mathrm{HR}$, hazard ratio. 

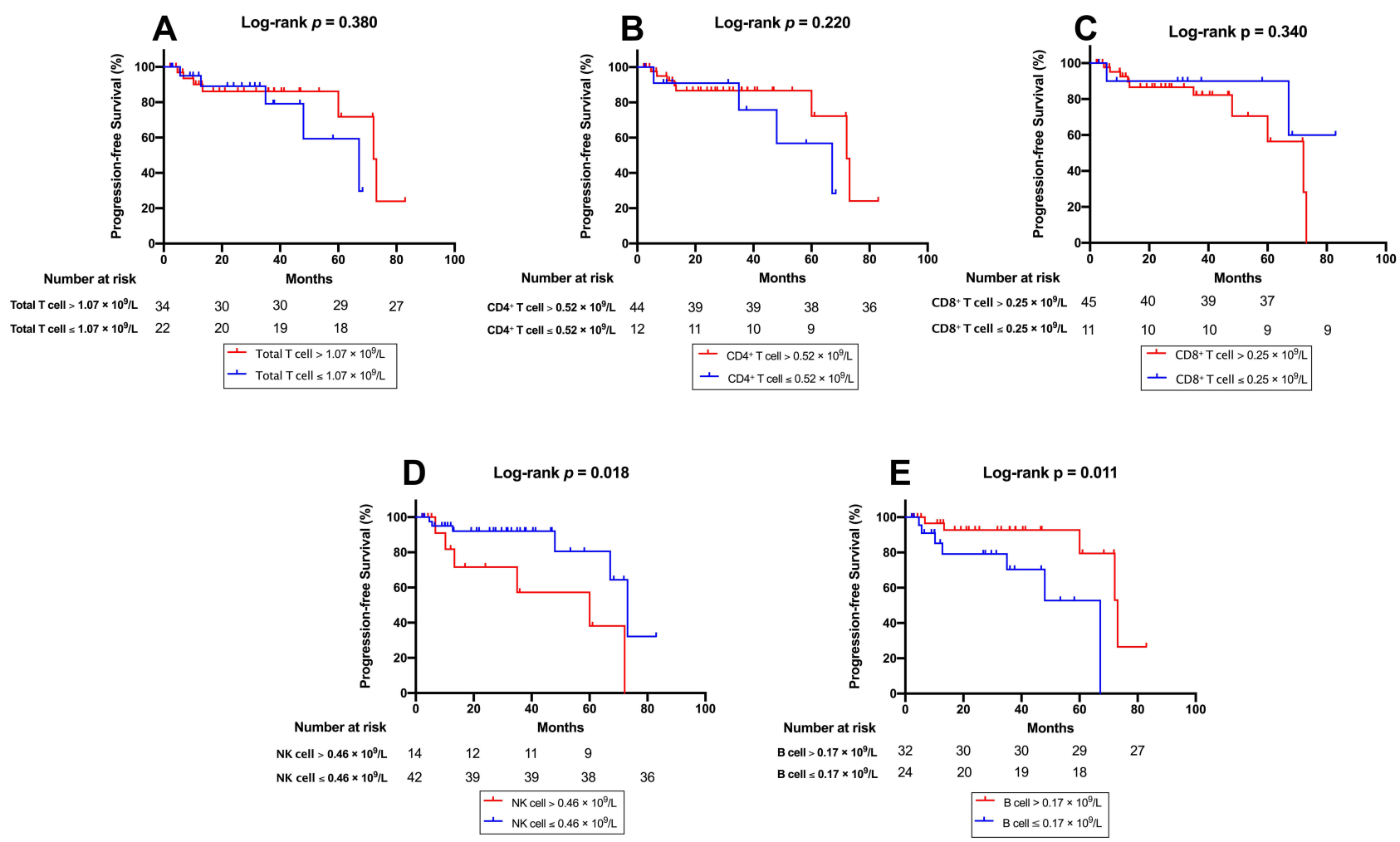

Figure 3 Kaplan-Meier curves for progression-free survival in patients following radical surgical resection $(n=56)$. (A) Absolute count of peripheral total T cells $>$ I.07 $\times$ $10^{9} / \mathrm{L}$ and $\leq 1.07 \times 10^{9} / \mathrm{L}$. (B) Absolute count of peripheral CD4+ T cell $>0.52 \times 10^{9} / \mathrm{L}$ and $\leq 0.52 \times 10^{9} / \mathrm{L}$. (C) Absolute count of peripheral CD8+ T cells $>0.25 \times 10^{9} / \mathrm{L}$ and $\leq 0.25 \times 10^{9} / \mathrm{L}$. (D) Absolute count of peripheral NK cells $>0.46 \times 10^{9} / \mathrm{L}$ and $\leq 0.46 \times 10^{9} / \mathrm{L}$. (E) Absolute count of peripheral $\mathrm{B}$ cells $>0.17 \times 10^{9} / \mathrm{L}$ and $\leq 0.17 \times 10^{9} / \mathrm{L}$. $\mathrm{P}$ value derived from Log rank tests.

antigen-specific immune responses and thus orchestrating the complex anti-tumour immune process that suppresses tumour progression and development. ${ }^{21}$ Most remarkably, CD4+ helper $\mathrm{T}$ cells are responsible for providing regulatory cytokines that are required for the priming of CD8+ cytolytic T lymphocytes, which are believed to function as the vital effector cells that execute tumour cell killing. ${ }^{22}$ Moreover, CD4+ helper T cells may also boost humoural immunity by activating $\mathrm{B}$ cells, thus stimulating antibody production. ${ }^{23}$ Several studies have reported that there are decreases in total T cells and CD4+ T cells in patients with metastasis, ${ }^{13,23,24}$ and total $\mathrm{T}$ cells and $\mathrm{CD} 4+\mathrm{T}$ cells were found to be lower in patients with cancer than in healthy people and to be lower in individuals with only primary tumours than in patients with one or more distant metastasis. ${ }^{25}$ We speculate that the decreases in total $\mathrm{T}$ cells and CD4+ cells were probably due to $\mathrm{T}$ cell exhaustion. T cell exhaustion is a state of $\mathrm{T}$ cell dysfunction that was originally reported in chronic viral infections but has recently been described in many types of tumours. $^{26,27} \mathrm{~T}$ cell exhaustion is characterized by the gradual and progressive impairment of $\mathrm{T}$ cell function and can ultimately result in the physical loss of $\mathrm{T}$ cells. ${ }^{28}$ $\mathrm{T}$ cell exhaustion was reported in both $\mathrm{CD} 4+$ and CD8+ $\mathrm{T}$ cells, and notably, the exhaustion of tumour-specific $\mathrm{CD} 8+\mathrm{T}$ cells was reported in metastasis from melanoma patients. ${ }^{26} \mathrm{~A}$ vicious cycle is thus formed, where an impaired immune status may lead to metastasis, and in patients with metastasis, the immune status is further compromised.

B cells predominantly function in humoural immunity, whose role in anti-tumour immunity, though less investigated than that of $\mathrm{T}$ cells, has attracted increasing attention. ${ }^{29}$ In addition to antibody secretion, B cells may also release cytokines that regulate other immune cells, orchestrating and regulating $\mathrm{T}$ cell and innate immune responses. Remarkably, B cells may enhance the activity of cytotoxic $\mathrm{T}$ cells and may have direct tumour-killing effects by secreting granzyme B and indirect tumoricidal effects that occur in an antibody-dependent manner. ${ }^{29}$ Therefore, B cells may play a crucial role in restricting tumour progression and development. Here, we 
demonstrated that peripheral B cells independently predict the progression of panNETs, which indicates that peripheral B cell levels may be a promising independent prognostic indicator in panNET patients and a potential target for panNET treatment.

We also noticed that, in contrast to B cells, a high absolute count of peripheral NK cells was associated with a shorter PFS and was an independent prognostic factor in patients that underwent radical surgical resection. This result was completely different from our hypothesis regarding NK cells, which are known to directly kill tumor cells through the release of toxic granules and to play a key role in suppressing tumor metastasis. ${ }^{30,31}$ In fact, multiple studies have reported similar results in various cancer types. Tietze et $\mathrm{al}^{32}$ reported that a low level of total peripheral NK cells may predict a better prognosis in melanoma patients than normal or high peripheral NK cell levels. Jonge et $\mathrm{al}^{11}$ reported similar results in melanoma patients and indicated that a certain type of NK cells may have an adverse effect on the anti-tumor responses by suppressing $\mathrm{T}$ cell activities via CD38, perforin, CD11a and IFN $\gamma$. Yang et $\mathrm{al}^{33}$ reported that a high absolute count of NK cells was associated with poor prognosis in pancreatic cancer patients. Though the anti-tumor activities of NK cells have been demonstrated and corroborated, mounting evidence on the pro-tumor and pro-metastatic role of NK cells in tumors is also emerging. First, the expression of NK cell receptors can be modified by tumor cells, which allows the tumor cells to evade the anti-tumor activity of NK cells. ${ }^{31}$ The levels of multiple receptors that may activate NK cells, including NKG2D, NKp30, NKp46, and perforin-positive NK cells, were found to be substantially downregulated in patients with pancreatic cancer, gastric cancer, and colorectal cancer, and these decreases were associated with tumor progression. ${ }^{34}$ Moreover, NK cells can also directly generate a pro-tumor microenvironment and may facilitate tumor metastasis. For instance, IFN- $\gamma$ and TNF- $\alpha$, two distinct anti-tumor cytokines released by NK cells, were reported to trigger the adaptive immune evasion of tumor cells and epithelial-to-mesenchymal transition (EMT), ${ }^{35}$ which is a phenotype-switching process that allows proliferative tumor cells to shift into a migratory and invasive state. $^{36} \mathrm{NK}$ cells may also cause tumor cells to acquire an EMT phenotype via the alteration of HLA-I, PD-L1, or NKG2D-L in tumor cells. ${ }^{35,37}$ Further, NK cells may promote tumor metastasis via the expression of matrix metalloproteinases (MMPs), which facilitate the degradation of the extracellular matrix and may, in turn, contribute to tumor cell migration and invasion, or via the tumorrelated persistent inflammation that is induced by NK cellsecreted IL-6 and IL-32. ${ }^{31}$

A major limitation of our study was that it was a retrospective cohort study that was conducted at a single centre with a limited sample size, a relatively short follow-up time and a relatively low progression rate. The lack of a mechanistic investigation leads to another weakness. Therefore, prospective cohort studies at multiple centres need to be further conducted. More studies are needed to examine the specific mechanisms of these phenomena. Additionally, we mainly investigated peripheral lymphocyte subsets instead of locally infiltrating lymphocytes in tumour tissue, principally because peripheral lymphocyte subset levels are easier to obtain. However, though the local immune environment may be partially reflected by systemic immune status, the relationship between locally infiltrating lymphocytes and peripheral lymphocytes warrants further corroboration. Moreover, important information such as post-surgical complications, pre-existing diabetes or pancreatitis, and the baseline nutritional conditions of patients were not included in our study, which may threaten the validity of our results. Prospective studies in larger cohorts with clear records of clinicopathological characteristics should be performed to validate our findings.

\section{Conclusion}

In conclusion, our study revealed that the distant metastasis of panNET patients is associated with lower numbers of peripheral total $\mathrm{T}$ cells and $\mathrm{CD} 4+\mathrm{T}$ cells. A low baseline absolute count of peripheral $\mathrm{B}$ cells and a high baseline absolute count of peripheral NK cells are associated with a shorter PFS in panNET patients. These results indicated the prognostic significance of peripheral B cells and NK cells for the progression of panNETs, making B cells and NK cells promising clinical parameters for predicting the prognosis of panNET patients and potential targets for panNET treatment.

\section{Abbreviations}

panNETs, pancreatic neuroendocrine tumors; panNECs, pancreatic neuroendocrine carcinomas; FDG, fludeoxyglucose; NK cells, natural killer cells; EUS-FNA, endoscopic ultrasound-guided fine-needle aspiration biopsy; PLB, percutaneous liver biopsy; PFS, progression-free survival; American Joint Committee on Cancer, AJCC; OS, overall survival; CT, computed tomography; MRI, magnetic resonance imaging; PET, positron emission tomography; RECIST, response evaluation criteria in solid tumors; ROC, 
receiver operating characteristic; HR, hazard ratio; HAIC, hepatic arterial infusion chemotherapy; TACE, transarterial chemoembolization; EMT, epithelial-to-mesenchymal transition; MMPs, matrix metalloproteinases.

\section{Ethics Approval and Informed Consent}

This study was approved by the Ethics Board of Shanghai Cancer Center, Fudan University, and all patients involved in this study provided informed consent for the use of their personal data for research purposes.

\section{Acknowledgments}

The abstract of this paper was presented at the European Society of Medical Oncology as a poster presentation with interim findings. The poster's abstract was published in "Poster Abstracts" in Annals of Oncology (2019) 30 (suppl_5): v194-v197 (10.1093/annonc/mdz245).

\section{Funding}

This work was supported by the National Natural Science Foundation of China (grant numbers 81625016, 81871940, 81902417), the Scientific Innovation Project of Shanghai Education Committee (2019-01-07-00-07-E00057), Clinical and Scientific Innovation Project of Shanghai Hospital Development Center (SHDC12018109), the Shanghai Natural Science Foundation (grant number 17ZR1406300), the Shanghai Cancer Center Foundation for Distinguished Young Scholars (grant number YJJQ201803), and the Fudan University Personalized Project for "Double Top" Original Research (grant number XM03190633).

\section{Disclosure}

The authors report no conflicts of interest in this work.

\section{References}

1. Cives M, Strosberg JR. Gastroenteropancreatic neuroendocrine tumors. CA Cancer J Clin. 2018;68:471-487. doi:10.3322/caac.21493

2. Halfdanarson TR, Rubin J, Farnell MB, Grant CS, Petersen GM. Pancreatic endocrine neoplasms: epidemiology and prognosis of pancreatic endocrine tumors. Endocr Relat Cancer. 2008;15(2):409-427. doi:10.1677/ERC-07-0221

3. Ries LAG, Keel GE, Horner MD. SEER survival monograph cancer survival among adults: U.S. SEER program, 1988-2001 patient and tumor characteristics Edited by. 2007;(07):1988-2001.

4. Falconi M, Bartsch DK, Eriksson B, Taal BG, Vullierme MP. ENETS consensus guidelines for the management of patients with digestive neuroendocrine neoplasms of the digestive system: well-differentiated pancreatic non-functioning. Neuroendocrinology. 2012;95(2):98-119. doi: $10.1159 / 000335587$
5. Franko J, Feng W, Yip L, Genovese E, Moser AJ. Non-functional neuroendocrine carcinoma of the pancreas: incidence, tumor biology, and outcomes in 2158 patients. J Gastrointest Surg. 2010;14 (3):541-548. doi:10.1007/s11605-009-1115-0

6. Madeira I, Terris B, Voss M, et al. Prognostic factors in patients with endocrine tumors of the duodenopancreatic area. Gut. 1998;43 (3):422-427. doi:10.1136/gut.43.3.422

7. Bettini R, Boninsegna L, Mantovani W, et al. Prognostic factors at diagnosis and value of WHO classification in a mono-institutional series of 180 non-functioning pancreatic endocrine tumors. Ann Oncol. 2008;19(5):903-908. doi:10.1093/annonc/mdm552

8. Sansovini M, Severi S, Ianniello A, et al. Long-term follow-up and role of FDG PET in advanced pancreatic neuroendocrine patients treated with 177Lu-D OTATATE. Eur J Nucl Med Mol Imaging. 2017;44(3):490-499. doi:10.1007/s00259-016-3533-z

9. Hamilton NA, Liu T-C, Cavatiao A, et al. Ki-67 predicts disease recurrence and poor prognosis in pancreatic neuroendocrine neoplasms. Surgery. 2012;152(1):107-113. doi:10.1016/j.surg.2012. 02.011

10. Hanahan D, Weinberg RA. Hallmarks of cancer: the next generation. Cell. 2011;144(5):646-674. doi:10.1016/j.cell.2011.02.013

11. De Jonge K, Ebering A, Nassiri S, et al. Circulating CD56 bright NK cells inversely correlate with survival of melanoma patients. Sci Rep. 2019;9(1):4487. doi:10.1038/s41598-019-40933-8

12. Yu Q, Yu C, Ling Z. Elevated circulating CD19 + lymphocytes predict survival advantage in patients with gastric cancer. APJCP. 2012;13(5):2219-2224. doi:10.7314/apjcp.2012.13.5.2219

13. Aliustaoglu M, Bilici A. The effect of peripheral blood values on prognosis of patients with locally advanced gastric cancer before treatment. Med Oncol. 2010;27(4):1060-1065. doi:10.1007/s12032009-9335-4

14. Chen DS, Mellman I. Oncology meets immunology: the cancer-immunity cycle. Immunity. 2013;39(1):1-10. doi:10.1016/j. immuni.2013.07.012

15. von Andrian UH, Mackay CR. T-cell function and migration-two sides of the same coin. $N$ Engl J Med. 2000;343(14):1020-1034. doi:10.1056/NEJM200010053431407

16. Cooper MA, Fehniger TA, Caligiuri MA. The biology of human natural killer-cell subsets. Trends Immunol. 2001;22(11):633-640. doi:10.1016/S1471-4906(01)02060-9

17. Andersen MH, Schrama D, Thor Straten P, Becker JC. Cytotoxic T cells. J Invest Dermatol. 2006;126(1):32-41. doi:10.1038/sj. jid. 5700001

18. Corthay A. How do regulatory $\mathrm{T}$ cells work? Scand J Immunol. 2009;70(4):326-336. doi:10.1111/j.1365-3083.2009.02308.x

19. Dunn GP, Old LJ, Schreiber RD. THE three es of cancer immunoediting. Аnпu Rev Immunol. 2004;22(1):329-360. doi:10. 1146/annurev.immunol.22.012703.104803

20. Ameri P, Ferone D. Diffuse endocrine system, neuroendocrine tumors and immunity: what's new? Neuroendocrinology. 2012;95 (4):267-276. doi:10.1159/000334612

21. Dilillo DJ, Yanaba K, Tedder TF, Alerts E. B cells are required for optimal CD4 + and CD8 + T cell tumor immunity: therapeutic B cell depletion enhances B16 melanoma growth in mice. J Immunol. 2010;184(7):4006-4016. doi:10.4049/jimmunol.0903009

22. Hung K, Hayashi R, Lafond-Walker A, Lowenstein C, Pardoll D, Levitsky H. The central role of CD4 $+\mathrm{T}$ cells in the antitumor immune response. J Exp Med. 1998;188(12):2357-2368. doi:10. 1084/jem.188.12.2357

23. Abbas A, Murphy KM, Sher A. Functional diversity of helper $T$ lymphocytes. Nature. 1996;383(6603):787-793. doi:10.1038/ $383787 \mathrm{a} 0$

24. Robinson E, Segal R, Sc B, et al. Lymphocyte subpopulations in patients with multiple primary tumors. Cancer. 1999;85 (9):2073-2076. doi:10.1002/(SICI)1097-0142(19990501)85:9<2073:: AID-CNCR26>3.0.CO;2-J 
25. Liu H, Deng W, Li J, Tang Y, Zhang L, Cui Y. Peripheral blood lymphocyte subset levels differ in patients with hepatocellular carcinoma. Oncotarget. 2016;7(47):77558-77564. doi:10.18632/ oncotarget.13041

26. Baitsch L, Rufer N, Speiser DE, et al. Exhaustion of tumor-specific CD8 + T cells in metastasis from melanoma patients find the latest version: exhaustion of tumor-specific CD8 + T cells in metastasis from melanoma patients. J Clin Invest. 2011;121(6):2350-2360. doi: $10.1172 / \mathrm{JCI} 46102$

27. Riches JC, Davies JK, Mcclanahan F, et al. LYMPHOID NEOPLASIA $\mathrm{T}$ cells from CLL patients exhibit features of T-cell exhaustion but retain capacity for cytokine production. Blood. 2019;121(9):1612-1622. doi:10.1182/blood-2012-09-457531

28. Yi JS, Cox MA, Zajac AJ. T-cell exhaustion: characteristics, causes and conversion. Immunology. 2010;129(4):474-481. doi:10.1111/ j.1365-2567.2010.03255.x

29. Tsou P, Katayama H, Ostrin EJ, Hanash SM. The emerging role of B cells in tumor immunity. Cancer Res. 2016;76(19):5597-5601. doi:10.1158/0008-5472.CAN-16-0431

30. López-Soto A, Gonzalez S, Smyth MJ, Galluzzi L. Control of metastasis by NK cells. Cancer Cell. 2017;32(2):135-154. doi:10.1016/j. ccell.2017.06.009

31. Lee HH, Kang H, Cho H. Natural killer cells and tumor metastasis. Arch Pharm Res. 2017;40(9):1037-1049. doi:10.1007/s12272-0170951-9
32. Tietze JK, Angelova D, Heppt MV, Ruzicka T, Berking C. Low baseline levels of NK cells may predict a positive response to ipilimumab in melanoma therapy. Exp Dermatol. 2017;26(7):622-629. doi:10.1111/exd.13263

33. Yang C, Cheng H, Zhang Y, Fan K, Luo G, Fan Z. Anergic natural killer cells educated by tumor cells are associated with a poor prognosis in patients with advanced pancreatic ductal adenocarcinoma. Cancer Immunol Immunother. 2018;67(12):1815-1823. doi:10.1007/ s00262-018-2235-8

34. Peng Y, Zhu Y, Zhang J, et al. Comprehensive analysis of the percentage of surface receptors and cytotoxic granules positive natural killer cells in patients with pancreatic cancer, gastric cancer, and colorectal cancer. J Transl Med. 2013;11(1):1. doi:10.1186/14795876-11-262

35. Lv N, Gao Y, Guan H, et al. Inflammatory mediators, tumor necrosis factor- $\alpha$ and interferon- $\gamma$, induce EMT in human PTC cell lines. Oncol Lett. 2015;10(4):2591-2597. doi:10.3892/ol.2015.3518

36. Thiery JP, Acloque H, Huang RY, Nieto MA. Epithelialmesenchymal transitions in development and disease. Cell. 2009;139(5):871-890. doi:10.1016/j.cell.2009.11.007

37. Dondero A, Pastorino F, Della Chiesa M, et al. PD-L1 expression in metastatic neuroblastoma as an additional mechanism for limiting immune surveillance. Oncoimmunology. 2015;5(1):e1064578e1064578. doi:10.1080/2162402X.2015.1064578

\section{Publish your work in this journal}

Cancer Management and Research is an international, peer-reviewed open access journal focusing on cancer research and the optimal use of preventative and integrated treatment interventions to achieve improved outcomes, enhanced survival and quality of life for the cancer patient.
The manuscript management system is completely online and includes a very quick and fair peer-review system, which is all easy to use. Visit http://www.dovepress.com/testimonials.php to read real quotes from published authors. 